\title{
PERENCANAAN PENGEMBANGAN BAURAN PEMASARAN \\ NASI LEMAK DI KEDAI KOPI PAGI SORE TANJUNG PINANG
}

\section{AMRI VANNUTURY SINAGA \\ MUMUH MULYANA}

Universitas Terbuka

\section{Ringkasan}

Bauran Pemasaran yang terdiri dari empat komponen menjadi penting untuk diperhatikan dan dikembangkan oleh pemasar agar berimplikasi positif terhadap perkembangan bisnis dan produk yang dipasarkannya. Perencanaan pengembangannya harus ditetapkan dan dilakukan berdasarkan kajian mendalam dengan memperhatikan stakeholder terkait. Perencanaan pemasaran meliputi perencanaan pengembangan produk, perencanaan pengembangan harga, perencanaan pengembangan promosi dan perencanaan pengembangan distribusi.

\section{Hasil Observasi}

1. Produk yang dijual adalah makanan lebih tepatnya Nasi Lemak di Kedai Kopi Pagi Sore Tj.Pinang
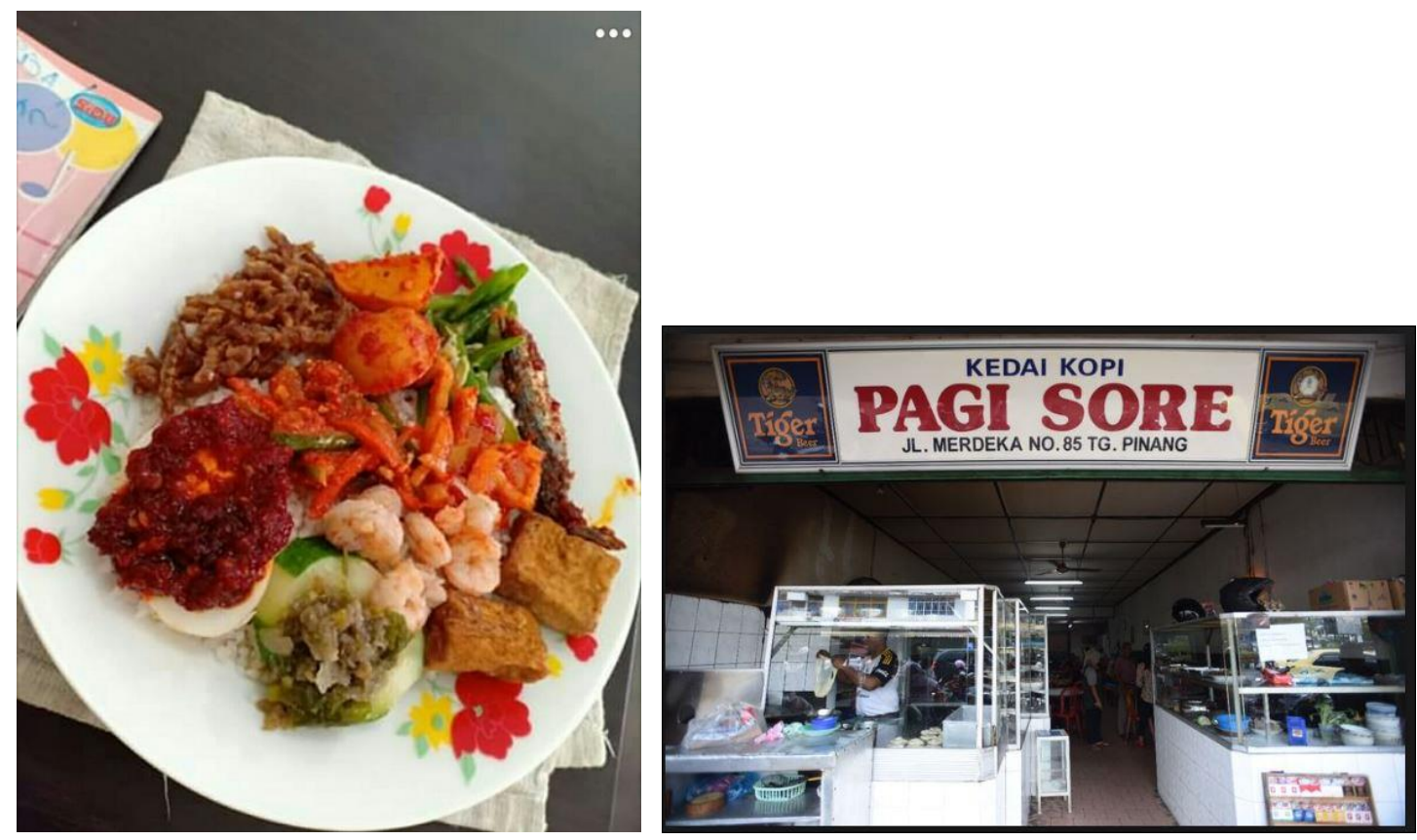
2. Harga jual dari nasi lemak tersebut adalah Rp12.000

3. Bentuk promosi yang dilakukan adalah gratis jasa pengantaran/free delivery

4. Bentuk pendistribusian yang dilakukan adalah langsung antar ke tempat.

a. Perencanan Pemasaran Pengambangan Produk yang dijual UKM tersebut dilakukan dengan inovasi kemasan, terutama untuk pelanggan yang ingin pesan ke rumah / tidak makan di lokasi.

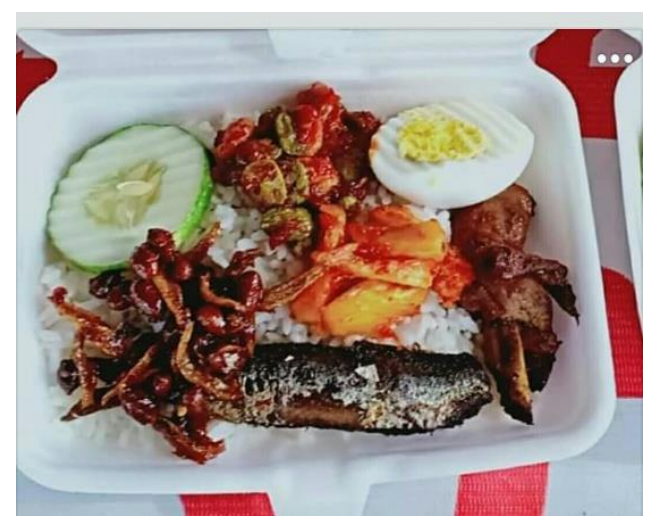

b. Perencanaan Pemasaran Penetapan Harga jual produk tersebut.

Harga adalah bagian dari alat pemasaran yang lebih mudah dan lebih cepat diubah dibandingkan dengan apabila kita mengubah kampanaye periklanan, merombak promosi penjualan. Oleh karena itu, nasil lemak tersebut dengan harga yang terjangkau di masyarakat yaitu Rp12.000. Penetapan harga tersebut dilakukan dengan metode harga dengan cost-plus yaitu dihitung berdasarkan mark-up biaya per unit produk. Harga Rp12.000 tersebut juga telah berdasarkan analisis harga yang dikenakan competitor produk yang mirip dengan produk nasi lemak yang dijual, dimana competitor rata-rata menjual produk yang mirip dengan nasi lemak yang dijual pada harga Rp14.000

c. Perencanaan Pemasaran untuk promosi yang tepat dilakukan UKM tersebut dilakukan pada media social seperti facebook (bursa jual beli), instagram dan lainnya. Promosi diberikan dalam bentuk jasa pengantaran. Untuk setiap pembelian jumlah produk makanan nasi lemak minimum dua diberikan jasa pengantaran secara gratis.

d. Perencanaan Pemasaran penggunaan saluran distribusi agar konsumen dapat mengakses produk tersebut dilakukan dengan cara saluran distribusi langsung (nol tingkat). Hal ini karena sifat produk tersebut tidak tahan lama dan merupakan produk 
yang langsung ditujukan ke konsumen akhir yaitu masyarakat. Cara yang dilakukan seperti melalui penjualan ketika terdapat perkumpulan seperti acara arisan ibu-ibu, pemesanan lewat telepon, media social seperti facebook, Instagram, online dan secara langsung melalui warung/kedai nasi lemak tersebut.

Referensi :

Mekaniwati, A. and Setiana, A., 2018. Interest Analysis on Sekolah Tinggi Ilmu Ekonomi Kesatuan Bogor Students With Motivation Approach, Personality and Entrepreneurial Characteristics. In THE INTERNATIONAL CONFERENCE ON ACCOUNTING AND MANAGEMENT SCIENCE (p. 309).

Mahardika, A.G., Pramiudi, U. and Fahmi, A., 2019. Peranan Penerapan Sistem Akuntansi Accurate Terhadap Penyusunan Laporan Keuangan (Studi Kasus Pada Umkm Toko Textile Leuwi Di Bogor). Jurnal Ilmiah Akuntansi Kesatuan, 7(1), pp.193196.

Nuraini, A., Gendalasari, G.G. and Sastra, H. 2017. Studi Peningkatan Pertumbuhan dan Nilai Perusahaan Sektor Perkebunan Melalui Analisis Kebijakan Dividend an Profitabilitas. Jurnal Ilmiah Manajemen Kesatuan, 5(2), pp.074-079.

UTAMI, S.B. and Wahyuningsih, D., 2019. EVALUASI PENGELOLAAN DANA KAS PADA DEPARTEMEN KONSERVASI SUMBERDAYA HUTAN DAN EKOWISATA IPB.

Wahyuni, I. and Wulan, R.S., 2019. Analisis Sistem Akuntansi Persediaan Bahan Baku Dalam Upaya Meningkatkan Pengendalian Intern. Jurnal Ilmiah Akuntansi Kesatuan, 7(1), pp.232-238.

Jasmadeti, J., Widyastuti, T. and Suyanto, S., 2018. PENGARUH PROFESIONALISME AUDITOR DAN PERTIMBANGAN TINGKAT MATERIALITAS TERHADAP KUALITAS AUDIT (Studi Empiris Pada Auditor KAP Jakarta Pusat). Jurnal Ilmiah Ilmu Ekonomi (Jurnal Akuntansi, Pajak dan Manajemen), 6(12), pp.155-175.

Listari, S. and Pardede, R.P. 2017. Pengaruh Fluktuasi Suku Bunga Kredit KURS terhadap Profitabilitas. Jurnal Ilmiah Akuntansi Kesatuan, 5(1), pp.8-14.

Pauziah, P. and Mulyana, M., 2018. Formulation of The Green Marketing Development Strategy for the Body Shop Botani Square Bogor. In THE INTERNATIONAL CONFERENCE ON ACCOUNTING AND MANAGEMENT SCIENCE (p. 171).

Amwila, A.Y. and Sudrajat, 2018. Identifying The Causes Why Some of The Households In Bogor Have Not Yet Utilized The Service of The Tirta Pakuan Water Company (Pdam) of Bogor. In THE INTERNATIONAL CONFERENCE ON ACCOUNTING AND MANAGEMENT SCIENCE (p. 297).

Hidayat, L., Mulyana, M. and Effendy, M., 2018. Membangun Kepuasan Mahasiswa Pengguna Laboratorium Komputer. JAS-PT Jurnal Analisis Sistem Pendidikan Tinggi, 1(2), pp.93-101. 